\title{
Dimensional Calculation of Automatic Soldering Station Chain Conveyor's Electric Motor
}

Miroslav Blatnický, Ján Dižo, Pavol Kurčík, Mária Blatnická

Faculty of Mechanical Engineering, University of Žilina. Univerzitná 8215/1, 01026 Žilina. Slovakia. E-mail: miroslav.blatnicky@fstroj.uniza.sk, jan.dizo@fstroj.uniza.sk,_pavol.kurcik@fstroj.uniza.sk, maria.blatnicka@fstroj.uniza.sk.

The paper deals with a design of required electric motor power for the conveyor line. This machine will serve for automatic soldering of a compressor outlet piping in a real company. The calculation of the motor is necessary to ensure a required handling of pallets with the compressors, i.e. between individual working positions. These positions consist of manual loading components on the line, automatic soldering and manual tightness control. After determining the power of the drive motor, it will be possible to produce a real prototype. The designed electric motor will be integrated into the machine and that will demonstrate the correctness of all design suggestions and calculations including the dimensional calculation of the drive motor in conjunction with the customer's technical standards requirements.

Keywords: Chain conveyor, soldering station, dimensional calculation, electric motor

\section{Introduction}

The successful development of mankind to the state we see today has its origin in distant past when the man had to fight for survival in the original living conditions.
Repeating successful activities that have brought about improved living conditions have also triggered brain activity, i.e. from simple logical operations to memorization and analysis. The result of this process was the creations of man, whose improvement led to progress consisting of the construction of machines and heavy machinery $[4,7]$.
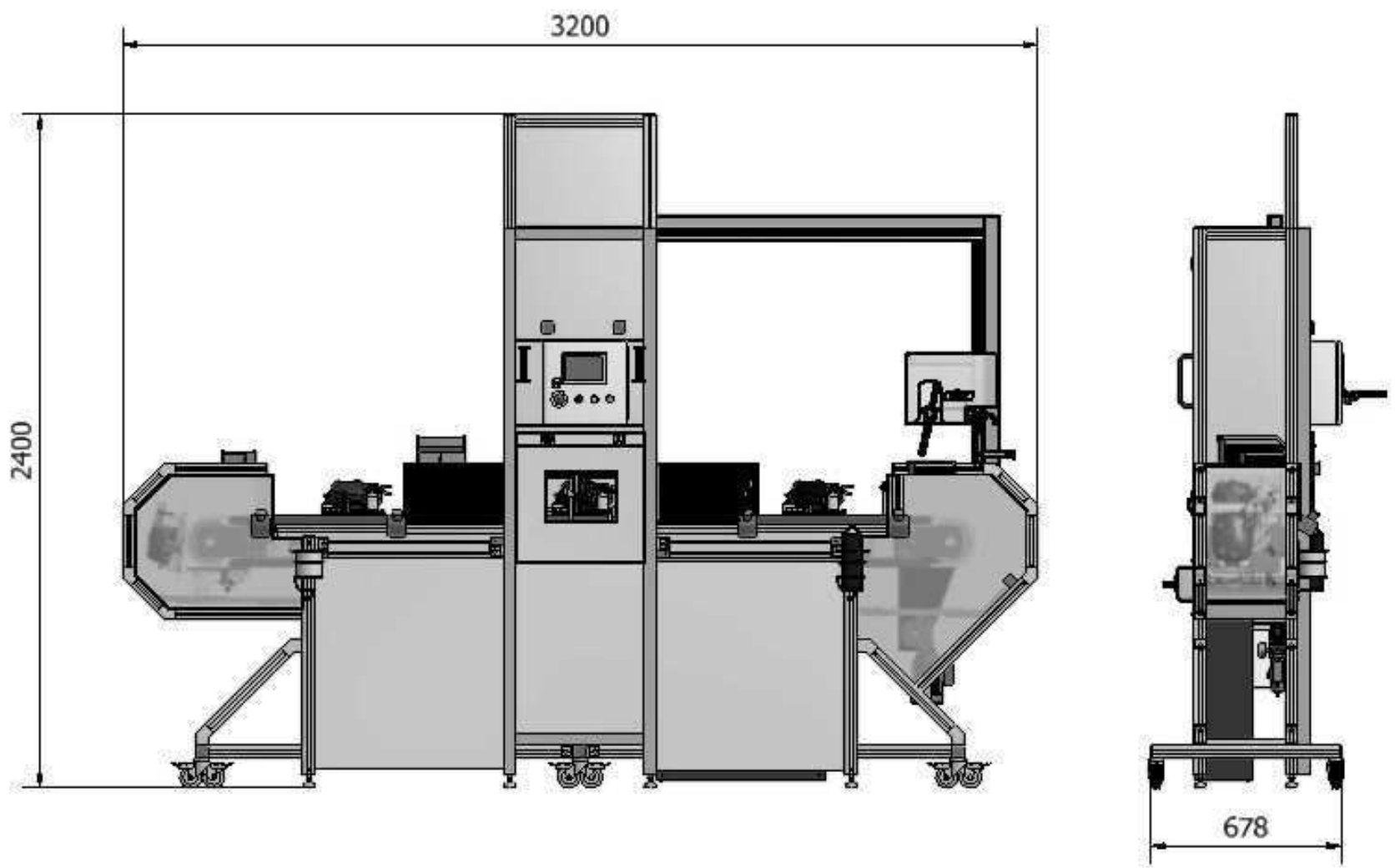

Fig. 1 Main dimensions of constructed machine

This process of developing technical systems that relieve man from repetitive physical work is called mechanization, and there is no need to talk too much about the importance of machinery for manipulating the material. Mechanisation is an important means of increasing productivity, quality and competitiveness of production. The effort is to make the individual working operations as short and simple as possible and to make them easy to learn while demanding a minimum of human effort [27]. Mechanisation greatly relieves man from heavy physical work, for example, in dangerous or harmful environments $[5,13]$. Today's advanced production is characterized by automation. Automation is a process in which the managerial function of a person is replaced by the activity of 
various machines and devices. Automation is a very complex process including very simple control operations performed on relatively simple devices, as well as very complex management of large production units. Controlling is a purposeful activity $[3,19]$ that evaluates and processes information about a controlled object or process, activities in that process (which may be data of measuring devices, statuses of signalising equipment and devices), and controls the devices in question to achieve the same prescribed purpose - in this case, it is the aim of designing a driving motor for constructional solution of chain conveyor (Fig. 1) for transporting a handling unit between individual working positions, the design must meet the requirements of the customer's technical standards $[9,16$, 17].

\section{Dimensional calculation input}

The asynchronous electric motor is most commonly used to drive a chain conveyor [20]. The drive assembly is then composed of an electric motor, a clutch and a gearbox and is typically mounted on a frame of the structure. Therefore, it is necessary to perform a dimensional calculation of the drive motor of this particular device, i.e. determine the required motor power $[1,2]$ to ensure smooth operation of the device. In the next step we will perform needed analyses by means of numerical methods $[2,14$, $23,24]$ and verify the accuracy of the calculations $[6,8$, $15,22]$.



Fig. 2 Schematic representation of the mechanism for the calculation (total number of pallets - 12, of which the maximum number of pallets loaded by compressors (in the upper branch) - 6; 6 empty pallets return in the lower branch)

In order to perform a precise analytical dimensional calculation of the electric motor's power, we need to input the data as accurate as possible like geometry (Fig. 2), mass, material, etc. in the systems. We can consider:

- Pallet mass $m_{l}=3.3 \mathrm{~kg}$

- Compressor mass

$$
m_{2}=5.2 \mathrm{~kg}
$$

- Chain linear mass density $m_{j}=1.32 \mathrm{~kg} \cdot \mathrm{m}^{-1}$

- Distance between drive axle and tensioner axle

$$
l=2,635.4 \mathrm{~mm}
$$

- Sprocket efficiency $\eta_{r k}=0.94(-)$

- Chain conveyor sprockets' diameters (drive and tensioner)

$$
D_{r k}=175 \mathrm{~mm}
$$

- $\quad$ Pallet movement speed $v_{p}=12 \mathrm{~m} \cdot \mathrm{min}^{-1}$

- Gravitational acceleration $g=9.81 \mathrm{~m} \cdot \mathrm{s}^{-2}$

- Coefficient of sliding friction (steel chain and chain support-POM material) $f=0.5(-)$.

Now we can begin by calculation of the chain total length $l_{r}$ (see Fig. 2) from the known input data using the relationship (1):

$$
{ }_{3} l_{r}=2 \cdot l+\pi \cdot D_{r k}
$$

By solving the equation (1) we get the total length of the chain $l_{r}=5,820.6 \mathrm{~mm}$. The chain mass $m_{r}$ will then be (2):

$$
m_{r}=m_{j} \cdot l_{r}
$$

By solving the equation (2) we get the total chain mass $m_{r}=7.7 \mathrm{~kg}$. A pitch spacing distance of pallets on the chain (Fig. 2) $R_{1}$ at a number of conveyor's pallets $p_{p}=$ 12 (-) will be (3):

$$
R_{1}=\frac{l_{r}}{p_{p}}
$$

By solving the equation (3) we get the pitch spacing distance of pallets on the chain $R_{l}=485 \mathrm{~mm}$. The magnitude of a weight causing the drive chain in the upper (loaded) part of the chain to be pressed against chain support (POM material), i.e., linear load $q_{1}$ will be (4):

$$
q_{1}=m_{j} \cdot g
$$

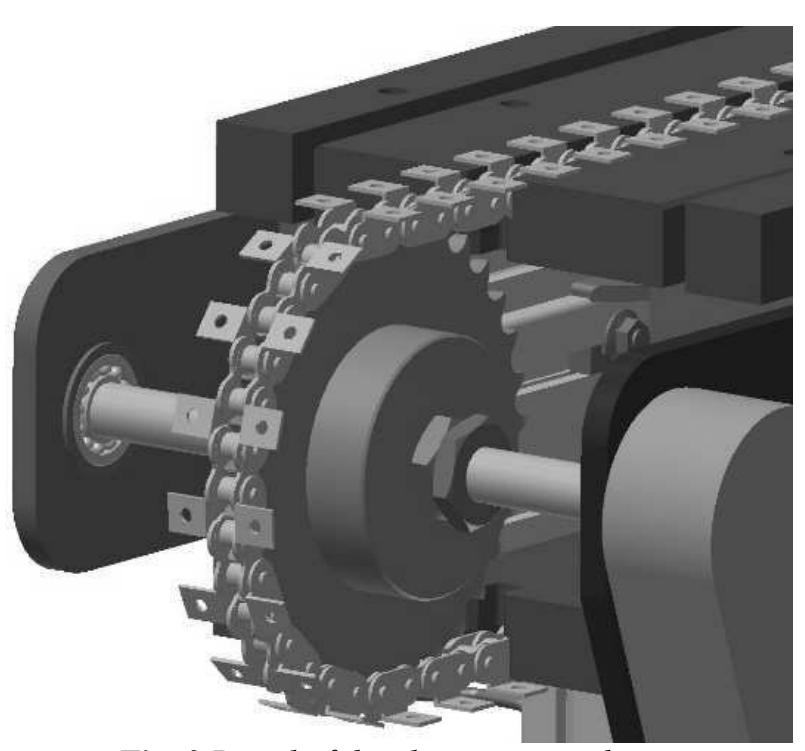

Fig. 3 Detail of the chain support design 
By solving the equation (4) we get the linear load from the upper part of the chain $q_{1}=12.95 \mathrm{~N} . \mathrm{m}^{-1}$. The weight of the chain $F_{g}$ will then be (5):

$$
F_{g}=q_{1} \cdot l
$$

By solving the equation (5) we get the weight $F_{g}=$ $34.13 \mathrm{~N}$. A weight $F_{g l}$ from pallet mass together with a loaded compressor will be (6):

$$
F_{g 1}=\left(m_{1}+m_{2}\right) \cdot g \text {. }
$$

By solving the equation (6) we get the weight of the pallet with the compressor $F_{g l}=83.4 \mathrm{~N}$. The total normal force $F_{N}$ causing the chain to be pressed against the guide (the support from material POM) for the most unfavourable case (fully loaded by $i=6$ pallets) will be (7):

$$
F_{N}=\sum_{i=1}^{6} F_{g 1 i}+F_{g}
$$

By solving the equation (7) we get the total normal force $F_{N}=535 \mathrm{~N}$. Corresponding friction force $F_{T}$ occurring in the chain and support contact, i.e. on the sprocket radius (see Fig. 3) will be (8):

$$
F_{T}=F_{N} \cdot f \text {. }
$$

By solving the equation (8) we get the total friction force $F_{T}=267.5 \mathrm{~N}$. A lower branch of the chain does not cause friction, however, it can express itself by increasing the overall resistance to movement as the moving mass increases and also it increases the pressure force in the upper branch of the chain (against the empty palettes and the chain). Therefore, and because of safety against an increase of the friction force, we choose a safety factor $k_{l}=$ $1.3(-)$. The value of the considered total friction force will then be (9):

$$
F_{T C}=F_{T} \cdot k_{1}
$$

By solving the equation (9) we get the total friction force $F_{T C}=347.75 \mathrm{~N}$. At this moment, all the important inputs that are involved in determining the required power of the electric motor are known.

\section{Determination of drive motor power}

Power of the drive motor $P_{o}$ with steady chain running can be determined by (10):

$$
P_{o}=\frac{F_{T c} \cdot v_{p}}{1000 \cdot \eta_{c} \cdot \eta_{p}}
$$

The efficiency of commonly used worm gears ranges from $\eta_{P}=0.54$ to 0.69 (-).Therefore, for the calculation we choose the value $\eta_{P}=0.6(-)$.

The overall mechanical efficiency of the conveyor without friction losses in chain can be determined as the product of the partial efficiencies $\eta_{r k}=0.94$ (-) of all sprockets used, i.e. the drive and tensioning sprocket on the belt and also two sprockets of side chain transmission used with the bearing (see Fig. 4) according to (11):

$$
\eta_{c}=\eta_{r k} \cdot \eta_{r k} \cdot \eta_{r k} \cdot \eta_{r k}
$$

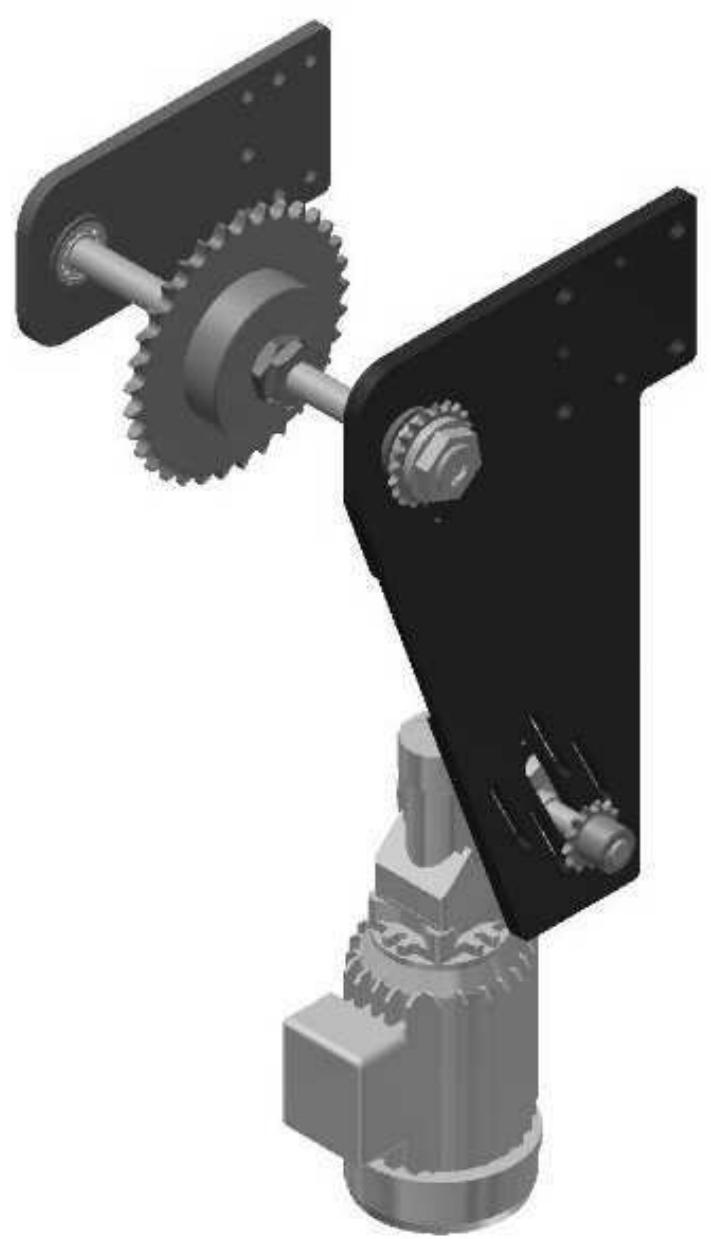

Fig. 4 Conveyor drive system

By solving the equation (11) we get the total mechanical efficiency of sprockets used $\eta_{C}=0.78$ (-). By substituting values into the equation (10) we get the required motor power $P_{O}=0.1485 \mathrm{~kW}$. According to this value, we select the motor with the designation MAXMA MDEMABR 063-32C1C with the values stated by the manufacturer:

- $\quad$ Rated power output

$$
\begin{aligned}
& P_{n}= \\
& M_{n} \quad= \\
& n \quad= \\
& \omega \quad= \\
& I \quad= \\
& \xi=2.1
\end{aligned}
$$
$180 \mathrm{~W}$

- Motor torque $1.26 \mathrm{Nm}$

- Motor rotational speed under load $n=$ 22.74 rev.s $^{-1}$

- Angular velocity $142.86 \mathrm{rad}^{-1} \mathrm{~s}^{-1}$

- Moment of inertia $0.00057 \mathrm{~kg} . \mathrm{m}^{2}$

- Torque overload $(-)$

However, the determination of the motor power at a steady rate does not have to match the required power at 
start-up. Therefore, it is necessary to check the motor for starting. Starting moment (12):

$$
M_{\text {rozb. }}=M_{T}+M_{Z P}+M_{Z R}+M_{F}+M_{S} .
$$

We can consider the value of inclined plane moment $M_{S}$ as zero because the pallets with compressors move in a plane. The friction moment $M_{T}$ which is reduced to the motor shaft is determined by (13):

$$
M_{T}=F_{T c} \cdot\left(\frac{R_{r k}}{r} \cdot r\right)
$$

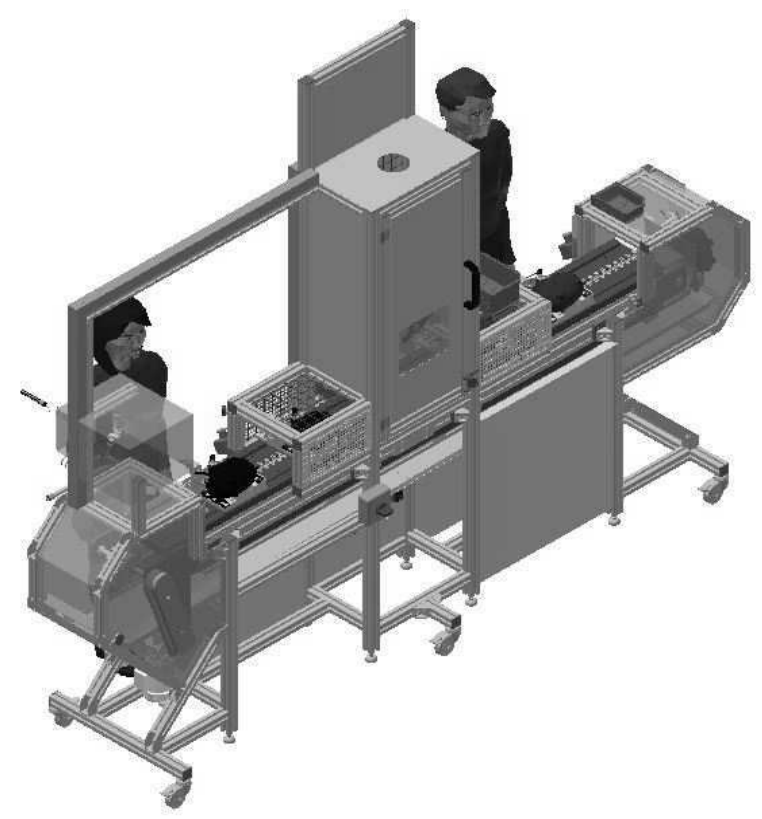

Fig. 5 3D model of overall machine design

In relation (13) $\mathrm{r}=50 \mathrm{~mm}$ is a radius of the sprocket on the electric motor shaft (see Fig. 4). The identical sprocket (of the same radius) is located on the common shaft with the drive sprocket. Therefore, the side chain transmission $r / r=1(-)$ is used. By solving the equation (13) we get the friction moment $M_{T}=30.43 \mathrm{Nm}$. Value of the inertial sliding mass moment $M_{Z P}$ reduced to the motor shaft can be determined by (14):

$$
M_{Z P}=F_{Z P} \cdot\left(\frac{R_{r k}}{r} \cdot r\right)
$$

Inertia force of the sliding mass $F_{Z P}$ can be determined using Fig. 2 and by (15):

$$
F_{Z P}=\left(12 \cdot m_{1}+6 \cdot m_{2}+m_{r}\right) \cdot a \text {. }
$$

Acceleration $a$ of the chain, pallets and also compressors can be determined from the chosen start time $t_{r}=0.3 \mathrm{~s}$ and from the required chain motion speed $v_{p}$ (16):

$$
a=\frac{v_{p}}{t_{r}}
$$

By solving the equations (16), (15) and (14) we get inertial sliding mass moment $M_{Z P}=4.58 \mathrm{Nm}$. Value of wind pressure moment $M_{F}$ can be considered zero because palettes with compressors will be moving in an engineering company's hall and thus we do not have to consider the force of the wind. Inertial rotating mass moment $M_{Z R}$ reduced on the motor shaft can be determined by (17):

$$
M_{Z R}=I_{\text {red }} \cdot \varepsilon \text {. }
$$

Angle acceleration $\varepsilon$ can be determined by (18):

$$
\varepsilon=\frac{\omega}{t_{r}}
$$

By solving the equation (18) we get angle acceleration $\varepsilon=476.2$ rad. $\mathrm{s}^{-2}$. Reduced moment of inertia $I_{\text {red }}$ of rotational mass to the motor's rotor can be determined by (19):

$$
I_{\text {red }}=\alpha . I .
$$

The factor $\alpha=1.2(-)$ takes into account the effect of other rotating masses outside the motor, as their effect decreases with the square of the gear ratio and the value $\alpha=$ 1.2 (-) illustrates this fact with sufficient precision. Then, by solving the equation (19) we get reduced moment of inertia $I_{\text {red }}=0.000684 \mathrm{~kg} \cdot \mathrm{m}^{2}$. By solving the equation (17) we get the inertial rotating mass moment reduced to the motor shaft $M_{Z R}=0.33 \mathrm{Nm}$. By substituting the determined values into the relation (12) we get the starting moment $M_{\text {rozb. }}=35.34 \mathrm{Nm}$. However, the real starting moment, which the motor has to overcome, is the quotient of the calculated starting moment $M_{\text {rozb }}$. and the gear ratio $i_{p}$ of the gearbox used because the calculated moment is based on the motor shaft but positioned ahead of the gearbox (see Figure 4). Therefore, (20):

$$
M_{\text {rozb.skut. }}=\frac{M_{r o z b .}}{i_{p}}
$$

We determine the gear ratio $i_{p}$ of the gearbox from the required input data. In order to maintain conveyor speed, the pallet has to move at a velocity $v_{p}=12 \mathrm{~m} \cdot \mathrm{min}^{-1}=0.2$ $\mathrm{m} . \mathrm{s}^{-1}$. This agrees with the corresponding speed of the drive sprocket $n_{r k}(21)$ :

$$
n_{r k}=\frac{v_{p}}{\pi \cdot D_{r k}}
$$

By solving the equation (21) we get the required sprocket speed $n_{r k}=0.364$ rev. $\mathrm{s}^{-1}$. The smaller sprocket mounted on this shaft has the same rotational speed, as they are firmly and axially connected (see Fig. 4). Since the side transmission used is of gear ratio 1:1 and hence the radiuses (diameters) of the drive and driven sprocket of the side transmission are the same, the speed of the second gear must also be the same.

The output shaft thus has this speed, i.e., $n_{p}=0.364$ rev.s ${ }^{-}$ 1 . The gear ratio of the gearbox must then be (22): 


$$
i_{p}=\frac{n}{n_{p}}
$$

By solving the equation (22) we get the required gear ratio of the gearbox $i_{p}=62.4(-)$. This calculation also determines the gearbox selection. We select the gearbox marked P045 FB 1/60 C18 P / B14 B3 from Lenze Slovakia, s.r.o. with a gear ratio of $i_{p}=60(-)$. From equation (20) we get the real starting moment $M_{\text {rozb.skut }}=0.6 \mathrm{Nm}$. In order the motor to fit the requirement of its start-up, the condition (23) must be met:

$$
M_{\text {rozb.skut. }} \leq \xi \cdot M_{n} \text {. }
$$

By solving the equation (23) we get $0.6 \mathrm{Nm}<2.1 \cdot 1.26$

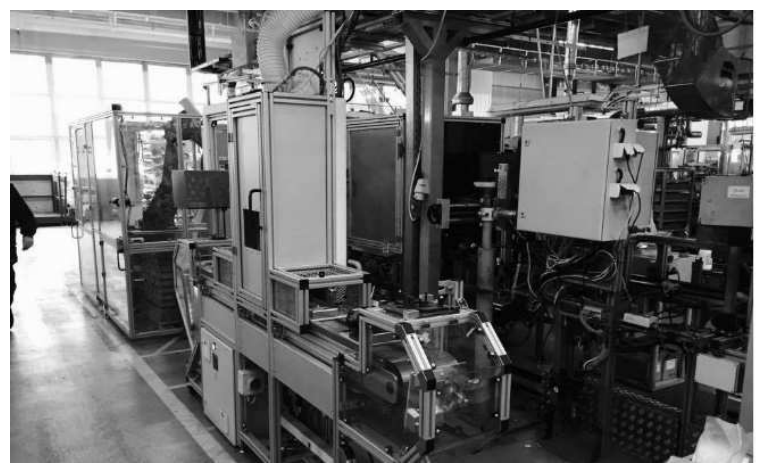

$=2.64 \mathrm{Nm}$ and therefore the proposed motor is suitable for driving this handling device (Fig. 5 and 6).

In the future research we will set up dynamical model $[11,18,26]$ of this device and we will study its dynamic properties, e. g. dynamical response etc. under various operational condition $[10,12,25]$.

\section{Conclusion}

Chain conveyors (Fig. 6 left), which represent one of the types of transport and handling equipment, interfere with their activities in all areas of the national economy. It belongs to a group of conveyors with a pulling element and can be defined as conveying machines where the function of the pulling element is filled with one or more closed chains circulating around the end sprockets.

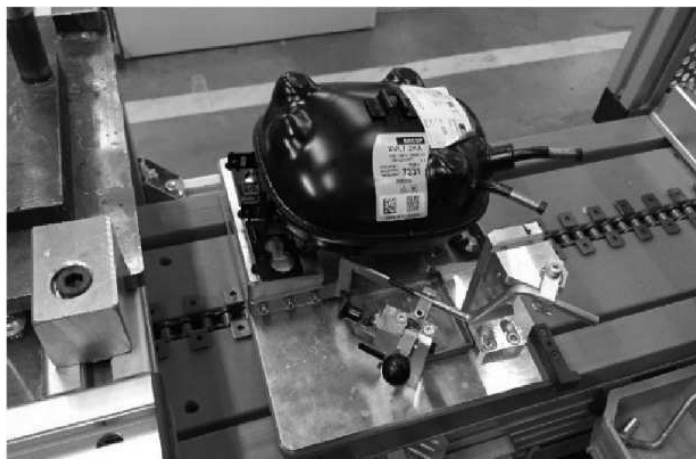

Fig. 6 The real prototype of the built equipment located at SECOP Zlaté Moravce (left) and Operator's view of work position no. 1 - manual loading the compressor on a pallet (right)

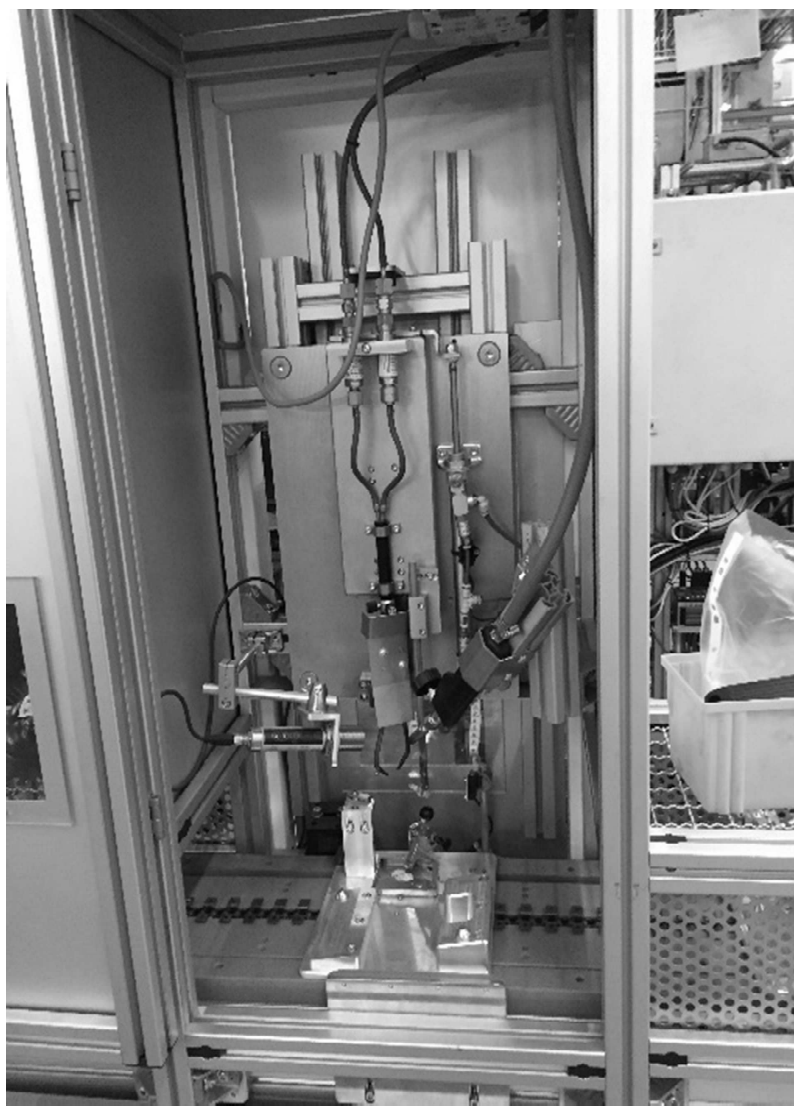

Fig. 7 View of the second operating position - automatic soldering position
The aim of this paper was partly the final design of the chain conveyor for the transport of the handling unit between the individual working positions (Fig. 6 right), which had to meet the requirements of the customer's technical standards, and partly the dimensional calculation of the drive motor. Currently, it can be stated that this objective was met as expected by the customer of the facility (SECOP, Zlaté Moravce), and all the requirements of the customer's technical standards were met.

According to the standards and requirements of the customer, the compressor outlet piping flame soldering station [21] has been designed with three operating positions: manual loading the compressor into a pallet with a soldering ring and tube; automatic flame welding (Fig. 7) when the compressor pallet stops at the welding station, the burner joins the welding point and the components are detached; and the third position is the manual station where the operator tests the tightness manually by inserting the compressed air hose into the compressor tube and checking the tightness with spray.

The proposed motor has been integrated into the machine and that now perform a function for which it was designed. This has proven the correctness of all design suggestions and calculations, including the dimensional calculation of the drive motor.

\section{Acknowledgement}

The work was supported by the Cultural and Educational Grant Agency of the Ministry of Education of the Slovak Republic in project No. KEGA 077ŽU-4/2017: 


\author{
Modernization of the Vehicles and engines study pro- \\ gram.
}

This work is the implementation result of the project: Modern methods of teaching control and diagnostics systems of engine vehicles ITMS 26110230107 supported by Operational Programme Education and funded European Social Fund.

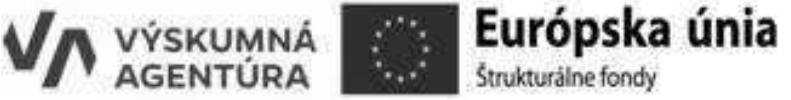

\section{References}

[1] BARAN, P., BREZÁNI, M., KUKUČA, P., ŠŤASTNIAK, P. (2017) Basic dynamical analysis and comparison of balancing systems of nonconventional piston machine FIK. In: Proceedia Engineering, Vol. 192, pp. 34-39, ISSN 18777058 .

[2] CHUDZIKIEWICZ, A., BOGACZ, R., KOSTRZEWSKI, M. (2014) Using acceleration signals recorded on a railway vehicle wheelsets for rail track condition monitoring. In: Proceedings of the $7^{\text {th }}$ European Workshop on Structural Health Monitoring, EWSHM 2014, (Le Cam, Vincent and Mevel, Laurent and Schoefs, Franck, (Ed.)), pp. 167-174. Nantes, France.

[3] CHUDZIKIEWICZ, A., MELNIK, R. (2012) Statistical analysis of vibration for the rail vehicle suspension monitoring system. Proceedings of the Mini Conference on Vehicle System Dynamics, Identification and Anomalies, VSDIA 2012, (I. Zobory, (Ed.)), pp. 261-269. Budapest: Budapest University of Technology and Economisc.

[4] GERLICI, J., LACK, T. (2014) Rail vehicles brake components test bench utilisation. In: $A p$ plies Mechanics and Materials, Vol. 486, pp. 379386, ISSN 1660-9336.

[5] GERLICI, J., LACK, T. (2014) Modified HHT method for vehicle vibration analysis in time domain utilisation. In: Applies Mechanics and Materials, Vol. 486, pp. 396-405, ISSN 1660-9336.

[6] GERLICI, J., LACK, T. (2009) Iterative method for railway wheel profile design. In: Komunikacie, Vol. 11, No. 2, pp. 49-56, ISSN 1335-4205.

[7] GERLICI, J., LACK, T., HARUŠINEC, J. (2014) Realistic simulation of railway operation on the RAILBCOT test stand. In: Applied Mechanics and Materials, Vol. 486, pp. 387-395, ISSN 16609336.

[8] GERLICI, J., LACK, T., KADOROVA, M. (2004) Calculation of the equivalent conicity function of the railway wheelset tread profile at the delta $\mathrm{R}$ function with a negative slope. In: Komunikacie, Vol. 6, No. 2, pp. 49-56, ISSN 13354205.

[9] GRENČÍK, J., RUMAN, F. (2015) Proposal of new maintenance scheme of air brake system on semi-trailer combination. In: Diagnostyka, Vol. 16, No. 2, pp. 11-19, ISSN 1641-6414.

[10] HARUŠINEC, J., MAŇUROVÁ, M., SUCHÁNEK, A. (2016) Optimalization of a brake unit in terms of control range. In: Manufacturing Technology, Vol. 16, No. 5, pp. 917-923, ISSN 1213-2489.

[11] HAUSER, V., NOZHENKO, O. S., KRAVCHENKO, K. O., LOULOVÁ, M., GERLICI, J., LACK, T. (2017) Impact of wheelset steering and wheel profile geometry to the vehicle behaviour when passing curved track. In: Manufacturing Technology, Vol. 17, No. 3, pp. 306-312, ISSN 1213-2489.

[12] HAUSER, V., NOZHENKO, O. S., KRAVCHENKO, K. O., LOULOVÁ, M., GERLICI, J., LACK, T. (2017) Proposal of a mechanism for setting bogie wheelsets to radial position while riding along track curve. In: Manufacturing Technology, Vol. 17, No. 2, pp. 186-192, ISSN 1213-2489.

[13] KOSTRZEWSKI, M. (2012) Logistics facilities designing method - a study of a procedure for logistics facilities designed and its OL09 software implementation. In: Archives of Transport, Vol. 24, No. 3, pp. 321-340, ISSN 0866-9546.

[14] LACK, T., GERLICI, J. (2012) Wheel-rail contact stress evaluation by means of the modified strip method utilization. In: Proceedings of the Mini Conference on Vehicle System Dynamics, Identification and Anomalies, VSDIA 2012, (I. Zobory, (Ed.)), pp. 261-269. Budapest: Budapest University of Technology and Economisc.

[15] LACK, T., GERLICI, J. (2016) Tangential stresses for non-elliptical contact patches computed by means of a modified FASTSIM method. In: Civil-Comp Proceedings, Vol. 110, No. 1, 10 pages, ISSN 1759-3433.

[16] LEITNER, B. (2013) Discrete optimization of the rail vehicle frame weight with respect to fatigue damage cumulation process. In: Proceedings of the $17^{\text {th }}$ International Conference Transport means 2013, Kaunas, Lithuania.

[17] LOULOVÁ, M., SUCHÁNEK, A., HARUŠINEC, J. (2017) Evaluation of the parameters affecting passenger riding comfort of a rail vehicle. In: Manufacturing Technology, Vol. 17, No. 2, pp. 224-231, ISSN 1213-2489. 
[18] MAŇUROVÁ, M., SUCHÁNEK, A. (2016) The analysis of a rail vehicle with a tilting bogie. In: Manufacturing Technology, Vol. 16, No. 5, pp. 1020-1027, ISSN 1213-2489.

[19] MELNIK, R., KOZIAK, S. (2017) Rail vehicle suspension condition monitoring - approach and implementation. In: Journal of Vibroengineering, Vol. 19, No. 1, pp. 487-501, ISSN 1392-8716.

[20] RUŽBARSKÝ, J., MAJERNÍK, R. (2017) Theoretical regulation of delimitation of metal level decrease in the furnace in case of pneumatic dosing device of metal. In: Manufacturing Technology, Vol. 17, No. 1, pp. 84-86, ISSN 1213-2489.

[21] SKOČILASOVÁ, B., SKOČILAS, J. (2015) Solidification of the aluminium alloy in the mold. In: Manufacturing Technology, Vol. 15, No. 5, pp. 909-914, ISSN 1213-2489.

[22] SMETANKA, L., GERLICI, J., LACK, T., PELAGIC, Z. (2015) Homogenization of fibers reinforced composite materials for simulation analysis. In: Manufacturing Technology, Vol. 15, No. 5, pp. 914-920, ISSN 1213-2489.

[23] SMETANKA, L., ŠŤASTNIAK, P. (2017) Analysis of contact stresses of theoretical and worn profile by using computer simulation. In: Manufacturing Technology, Vol. 17, No. 4, pp. 580585, ISSN 1213-2489.

[24] ŠŤASTNIAK, P., SMETANKA, L., MORAVČÍK, M. (2017) Development of modern railway bogie for broad track gauge - Bogie frame assessment. In: Manufacturing Technology, Vol. 17, No. 2, pp. 250-256, ISSN 12132489.

[25] STEIŠŪNAS, S., BUREIKA, G. (2014) Study of freight wagon running dynamic stability taking into account the track stiffness variation. In: Transport problems, Vol. 9, No. 4, pp. 131-143, ISSN 1896-0596.

[26] SUDA, Y., GRENCIK, J. (1996) The mechanism of enhanced curving performance of unsymmetric suspension trucks under action traction/brake torque. In: Vehicle system Dynamics, Vol. 25, No. SUPPL., pp. 629-640, ISSN 0042-3114.

[27] SVOBODA, M., SOUKUP, J., JELEN, K., KUBOVÝ, P. (2015) Effect of impact on human head. In: Manufacturing Technology, Vol. 15, No. 2, pp. 226-231, ISSN 1213-2489. 